\title{
El sujeto fuera del ser. \\ Reconstitución de la subjetividad en la filosofía de Emmanuel Lévinas
}

\author{
Patricia Castillo Becerra \\ Universidad de Guanajuato
}

Resumen

Este escrito pretende retomar la andadura intelectual de la concepción de la subjetividad en la filosofía francesa contemporánea, desde la crítica heideggeriana a la conciencia como fundamentum inconcussum hasta la radicalización de la subjetividad como humanidad, presentada por Lévinas en los escritos de su madurez. Para explicar dicho decurso, haremos hincapié en los señalamientos sobre la metafísica de la presencia como fundamentación del cariz epistemológico que la mantenía anclada a un discurso sobre la manutención, impidiendo así que sus rendimientos respecto a lo humano fueran ampliados.

Palabras clave: Heidegger, ontología, subjetividad, Lévinas, humanismo.

\section{Abstract}

This paper aims to resume the journey of intellectual conception of subjectivity in contemporary French philosophy, from Heidegger's consciousness as fundamentum inconcussum to the radicalization of subjectivity as humanity, presented by Levinas in his mature writings. To explain this haul, we emphasize that the signs on the metaphysics 
of presence as a foundation of epistemological point that kepted anchored to a discourse on the maintenance, thus preventing their yields relative to the human were extended.

Keywords: Heidegger, Ontology, Subjectivity, Levinas, Humanism.

$\square$ s de reconocimiento generalizado en el ámbito académico que la filosofía de Emmanuel Lévinas se encuentra dentro de la pauta de la eticidad, pero también es bien sabido que su filosofía presenta múltiples ristras que deben ser consideradas para dimensionar dicha pauta desde sus fondos conformantes. Nuestro interés en este ensayo es desvelar los fundamentos y raíces que, desde la filosofía de Heidegger, podemos reconocer como uno de sus posibles abordajes. La lectura atenta y crítica del pensador de la selva negra dibujó los derroteros desde los cuales se mantendrían los cuestionamientos que acompañarían a Lévinas desde sus tempranos diálogos con el pensador alemán hasta el sobrepasamiento de sus andamiajes, llevado a cabo, sobre todo, en la filosofía de su madurez.

Se ha afirmado ya que el problema central de la filosofía de Lévinas es "superar una definición de la subjetividad y proponer otra más allá del ser” (Urabayen, 2005: 97). En dicha afirmación se resume, más no se agota, el entendimiento de aquello que aún reluce de las problemáticas abiertas por sus predecesores intelectuales. Por ahora es interesante reconocer a Lévinas como dialogante y crítico de la ontología heideggeriana, desde el exordio que impulsa a un cambio de perspectiva en el seno del pensar occidentalista.

\section{La pregunta por el ser, el precedente heideggeriano}

A partir del cambio de perspectiva y tratamiento que desde la ontología heideggeriana se dio a la configuración del andamiaje fi- 
losófico contemporáneo, es posible una pauta interpretativa del clima general de la gesta de la ontología que incluyó una relectura de sus enclaves fundamentales. Desde la filosofía desarrollada en su gran obra, Sein und Zeit, se preconizaba una fundamentación que trataría de desmarcarse de toda estratificación anterior del ser humano. Comenzaba por afirmar que si este ser humano inquiere, lo hace de acuerdo con un modo de ser eminentemente comprensivo, inherente al filosofar. La lectura y la cuña desde las que desplegaría Sein und Zeit tienen un anclaje distinto, que sobradamente ha sido mal entendido cuando se quiere simplificar dicha filosofía en una doctrina. La verdadera liza de esta ontología, como Heidegger mismo insiste, preconizará contra los malos entendidos y los sobreentendidos respecto al ser como fundamentum inconcussum (Vid. Bengoa Ruiz de Azúa, 2009: 20).

Por lo anterior, lo que tiene que plantearse primero es que la filosofía ya no es el último reducto de racionalidad, no es la donadora de verdades y de solución de problemas, sino que se problematizará y se convertirá en exposición de preguntas. La configuración del cuestionamiento por el ser se torna así en la intención de su obra primordial y podría decirse que incluye su revisión aceptual en la historia de la filosofía, pero al unísono de la pregunta por el ser habría que inquerir retrospectivamente por el autor de la pregunta, por ello aparecería en el panorama el irresuelto carácter constitutivo del Dasein.

\section{La metafisica de la subjetividad}

No es nuestra intención agotar por ahora todos los emplazamientos desplegados por Heidegger para hacer comprensible el carácter de su ontología, simplemente marcamos lo que, respeto a la lectura de la subjetividad moderna, ha destacado como diferencia respecto a la analítica del Dasein. Dicha analítica está orientada 
por entero hacia la tarea de la elaboración de la pregunta por el ser, que le sirve de guía. Aunque esto quedará esclarecido desde el trazo medular de tal proyecto, se advierte que el análisis que se presenta desde algunas de sus ristras sólo tendrá un carácter provisorio. Lo anterior para reiterar en la defección de cualquier asunción subjetivista de la existencia. De esto deviene la utilización de la ilación de los existenciales. La reiteración del hiato incide en tratamientos antropológicos, psicologistas y/o subjetivistas que, en efecto, esta analítica trata de superar; entonces:

¿cómo hay que entender al hombre en su relación con el ser?

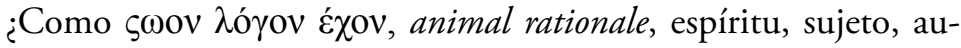
toconciencia? Heidegger rechazará todas estas concepciones del ser humano, porque fundan sus diferentes modos de acceso a las cosas en la percepción sensible y la razón; en otras palabras, porque comprenden la realidad de las cosas existentes en el mundo exclusivamente desde el prisma de la teoría (Escudero, 2010: 26).

De acuerdo con esto, en escritos como Nietzsche y ¿Qué es metafisica?, Heidegger insistirá en que ya no es posible la identificación de la esencialidad humana como subjetividad moderna. La reconfiguración de una ontología que lleva de fondo la autocomprensión de la existencia no podría ser concebida a menos de que se abandonara el cariz teorético que ha marcado el pensar filosófico y, aunado a ello, se distinguiera a la filosofía confeccionada desde su época como un distanciamiento a lo que él denomina metafísica de la subjetividad. La metafísica de la subjetividad es reconocida por Heidegger prácticamente en todas las etapas de la filosofía: en primera instancia como tendencia a la explicación óntica, es decir, la metafísica siempre ha eludido la cuestión del ser; en segunda instancia, todo el pensar metafísico ha privilegiado al upokeimenon, al sub-iectum que pondera la verdad de los acontecimientos y la exactitud de las explicaciones. En dicha metafísica, incluida la 
de Hegel y Niezsche, se sostiene la esencialidad del hombre como animal rationale ${ }^{1}$ (Heidegger, 2000: 164).

Nos preguntamos: ¿cómo se llega a una posición acentuada del "sujeto"? ¿De dónde surge ese dominio de lo subjetivo que guía toda colectividad humana y toda comprensión del mundo en la época moderna? La pregunta se justifica porque hasta el comienzo de la metafísica moderna con Descartes, e incluso dentro de esta metafísica misma, todo ente, en la medida en que es un ente, es comprendido como sub-iectum. Sub-iectum es la traducción e interpretación latina del upokeimenon griego y que significa lo que subyace, lo que está a la base, lo que desde sí ya yace delante. Con Descartes y desde Descartes, el hombre, el "yo" humano, se convierte en la metafísica de manera predominante en "sujeto". ¿Cómo llega el hombre al papel de auténtico y único sujeto? ¿Por qué este sujeto humano se traslada al "yo", de manera tal que la subjetividad se torna equivalente a la yoidad? ¿Se determina la subjetividad por la yoidad o, a la inversa, ésta por aquélla? De acuerdo con su concepto esencial, "subiectum" es lo que en un sentido destacado está ya siempre delante de y, por lo tanto, a la base de otro, siendo de esta forma fundamento (Heidegger, 2000: 119).

En este sentido, podemos ver que fue Heidegger quien inicio con aquel tratamiento que más tarde Lévinas reconocerá como la metafísica de la presencia, ya que podemos encontrar en la caracterización de la subjetividad las notas respecto al sostenimiento de la fórmula "uno frente al otro", que en el seguimiento de Heidegger implicaba al sujeto aportando el fundamento al ente, fórmula que, según el pensamiento heideggeriano, se ha mantenido desde Descartes a Husserl.

${ }^{1}$ En cada una de estas figuras de la subjetividad incondicionada, la esencia del hombre se integra en un papel diferente. De modo general y permanente, la esencia del hombre se ha fijado a lo largo de la historia de la metafísica como animal rationale. 


\section{La metafísica de la presencia}

Es conocido por Lévinas el movimiento de desmontaje conceptual que se desarrolló en la filosofía heideggeriana. Es conveniente decir que hay redes de interés que pusieron al pensamiento levinasiano dentro de la misma línea de deconstrucción de dicha fórmula, donde se emplea la subjetividad moderna para la recuperación de la existencia como processus. Empero, la lectura de Lévinas encontrará aún así una manutención en la ontología de corte heideggeriano, un panorama que no rompía del todo con el esquema representativo.

De tal modo que el intento por parte de Lévinas de subvertir el quicio de la subjetividad del ordo heideggeriano señalaba aún la plenitud de una comprensibilidad que representa para conformarse (Vid. Lévinas, 2001a: 237). De acuerdo con Lévinas, esto implica una manutención de la presencia del ente en la comprensión como aprehensión. Asimismo, Lévinas reconoce que si bien Heidegger ha cuestionado la identificación entre ser y pensar como el baluarte de la filosofía antigua, por ser la guía del pensamiento hegemónico y por no mostrar la esencia del ser-humano, en dicha identificación se mantiene un anquilosamiento, una adecuación del otro que se presenta desde el ser que representa. "La entrada del ser otro en el horizonte del ser que se lo representa es ipso facto adecuación" (Lévinas, 2001b: 91).

Según Lévinas, tendremos que reconocer que el problema estriba en la necesidad de ser representado todo lo otro desde una mismidad, desde una existencia que se esencia desde tal representación. En esto consiste la guisa de la ontología heideggeriana, que al preguntarse por el ente parte aún de la representatividad del ente dado y de la generalidad a la que conlleva como pensamiento respecto al ser. En este mismo tenor, Derrida sostendrá que esta aprehensibilidad, necesaria para la configuración de la comprensión, constituye la médula de la metafísica de la presencia: 
La metafísica de la presencia reconoce como ley única la mirada que recoge y desplaza lo disponible para hacerlo presente, pero su mirada está siempre afectada por una irritación que perturba la pura facultad de ver y contra la cual se vuelve permanentemente para acceder a la pureza, sin poder reconocer que esa irritación no es otra cosa que la misma facultad de ver (Fragasso: internet).

En la metafísica de la presencia, que no es otra cosa que la crítica al discurso de la ontología, se señala la neutralización de lo otro:

La metafísica, posterior de hecho, como crítica de la ontología, es por derecho y filosóficamente primera. Si es verdad que "la filosofía occidental ha sido las más de las veces una ontología» dominada desde Sócrates por una Razón que no recibe más que lo que ella se da a sí misma, que no hace jamás sino acordarse de sí misma, si la ontología es una tautología y una egología, es que ha neutralizado siempre, en todos los sentidos de la palabra, lo otro (Derrida, 1989: 131).

Asimismo, Lévinas duda de la generosidad del ser que se busca resignificar en la ontología, ese donarse del ser (es gibt) implica para Lévinas una manutención de la presencia. "Donación de la alteridad en la presencia, no solamente en el sentido metafórico del término, sino donación que cobra sentido en el horizonte concreto de un aprehender referido ya a un "tener entre manos" [...] Y ello es seguramente el erigirse mismo de la cosa y del (algo), de la configuración del ente en el ser, en la presencia” (Checchi, 1994: 188). Por ello, Lévinas realizó un esfuerzo por sacar de la terminología de la ontología su caracterización de la subjetividad, que inquiere como necesario un replanteamiento a partir de los márgenes de tal discurso, cuyo fondo común es la absorción de todo lo otro con referencia a un yo ateo y egoísta. Tal egoísmo es el principio de la constitución de la identidad, que en Lévinas no aludirá más al principio de identidad de la lógica y de la ontología, porque en ese principio se da la gloria de la unidad del pensar por sí: "El prin- 
cipio de identidad habla del ser de lo ente. El principio vale sólo como ley del pensar en la medida en que es una ley del ser que dice que a cada ente en cuanto tal le pertenece la identidad, la unidad consigo mismo" (Heidegger, 1990: 67). Dicho principio se disuelve en la terminología ética fundada en el lenguaje ontológico, pero dimitida en la etapa media y tardía de su filosofía.

Es a partir de la reluctancia al pensamiento sobre el ser, desde un planteamiento objetivo donde el sujeto es difuminado como correlato del objeto y su significación, aparece subordinada a la del objeto, donde un Lévinas maduro ha vislumbrado su pensar propio. A partir de esta crítica intentará replantear el carácter de la humanidad fuera del pensamiento reflexivo, fuera del pensamiento sobre el Ser, porque es un pensamiento masificado en la presencia, pero sobre todo porque comienza con la unicidad del sujeto y el objeto. Al respecto, apunta brillantemente Antonio Pintor Ramos:

Pues bien, el pensamiento de Lévinas coloca en su centro la subjetividad, pero no significa esto ningún retroceso sobre las críticas de Heidegger (antes de Nietzsche) o del estructuralismo. Lévinas entiende que la verdadera subjetividad queda neutralizada cuando es concebida en la línea de la conciencia teórica que iguala a todos los sujetos en un discurso homogéneo e impersonal (Lévinas, 2003: 26- 27).

Lévinas emprende, sobre todo en los escritos de madurez, una reconstitución de la subjetividad, cuyo primer escenario ha tomado en cuenta mayoritariamente la defección de la conceptualización del ser como presencia, cuyo telos es la posibilidad de pensar más de lo que se piensa, desbordando los márgenes de un pensamiento que no es lo mismo que el ser, que está entregado al otro:

El aparecer del ser no se separa de una cierta conjunción de elementos en estructura, de un arracimamiento de las estructuras en las cuales el ser desarrolla su movimiento, de su simultaneidad, es 
decir, de su co-presencia. El presente, el tiempo privilegiado de la verdad y del ser, del ser en verdad, es la misma contemporaneidad y la manifestación del ser es re-presentación (Lévinas, 2003: 208).

El pensamiento sobre el ser, que posteriormente Lévinas identificará como el psiquismo, está afianzado en el carácter de lo idéntico, que en tales términos aludían a la autenticidad del yo. (Cfr. Lévinas, 2001a: 235).

Recordemos que ese acontecimiento del ser, su comprensión, sólo se da en las manos de un Dasein auténtico, propio, que asume la responsabilidad del planteamiento de la pregunta fundamental y la responsabilidad de encontrar la respuesta. La autenticidad y la propiedad que remarca es la que tiene que ver con la identidad, con lo idéntico en cuanto a una consagración humana, a un yo no intercambiable, a una yoidad constituida como Eigentlichkeit, a un pensamiento que articula la pregunta por el ser. La acogida del ser por parte del pensamiento es exclusiva de aquel ser que se pregunta y se preocupa por el advenimiento del ser, es un ser que en cada caso es el mío.

Empero, Lévinas apunta que en esta caracterización del Dasein propio se le presenta siempre desde una exención a la ambigüedad y a los recursos interiores. Esto está expresado en "Morir por", conferencia en la que se pronunciaba la denuncia y renuncia a la prosecución de los atavismos ontológico-heideggerianos, para tornarse hacia el humanismo: "Esta forma de acoger en Sein - la aventura del ser- en el pensamiento, es una interrogación acerca del ser y de su sentido, esta acogida del ser en el pensamiento, en el modo del estar-ahi humano, en el modo del Da-sein, descrita con tal genialidad, ¿está exenta de ambigüedades?” (Lévinas, 2001a: 231).

El paso de la Eigentlichkeit a la vulnerabilidad es la impronta verdadera que deja Lévinas al re-pensar la subjetividad, una subjetividad que en la filosofía contemporánea, en palabras de Forthom- 
me, se encontraba disuelta, ${ }^{2}$ hecho que obedece principalmente al contexto histórico que marca la participación de nuestro autor en el pensamiento occidental. De tal modo, la tarea de la reconstitución de la subjetividad era mostrarla en principio desde un escenario previo a la ontología, desarrollado sobre todo en Totalidad e infinito, en donde dicha subjetividad, cuya morada radica en la corporalidad, se encuentra transida de gozo, deseo, cansancio, aburrimiento; pero que tiene como principio a un sujeto que, después de verse conformado, concibe su propia vulnerabilidad y, después, su inquietud por la absoluta otredad. De este modo, lo que Lévinas emprende en Totalidad e infinito es una defensa de la subjetividad, no como defensa de la ipseidad sino como una crítica al hecho de que la humanidad resida en una posición autónoma a la identidad del Yo.

Vázquez Moro reconoce que esto incluye, en "un primer momento", la tentativa de pensar la posibilidad de la ruptura de la esencia en el interior de la subjetividad humana que, "brecha" o "fisura" del ser y de su privilegio filosófico, aparecerá como una dirección hacia el más allá. Hacia la trascendencia metafísica que la ontología misma supone (Cfr. Vázquez Moro, 1982: 19).

\section{La metafísica de la trascendencia, salida del ser como presencia}

Para Lévinas, hay una relación metafísica que puede sostenerse de lleno aún en un estadio postmetafísico como el suyo: la relación

2 «Ainsi Lévinas ne s'attache à mettre en valeur l'hypostase (l'avenement du sujet) ou l'identification concrète du Même, que parce qu'une philosophie de la transcendance ne peut s'eriger si le Moi est dissous — comme il l'est par la philosophie contemporaine: la dé-position de la transcendance ne peut se passer sans la position du Moi ou comme une dissolution de celui-ci. En fait, c'est la transcendance elle-même —comme exposition à l'Autre- qui demeure l'essentiel de ce que Lévinas voulu nommer» (Forthomme, 1979: 8). 
metafísica con el ente, que es un más allá de toda esencia y de todo proceso del ser, es decir, la verdadera trascendencia. Estas intenciones están descritas en lo que Forthomme describe como la metafísica de la trascendencia, que implica una excedencia o una evasión del lecho del ser. Lo cual representa una de las intenciones de la filosofía levinasiana, cuyo esfuerzo radica en posarse más allá de la esencia (esse a diferencia del ens), barruntando la trascendencia, bajo las efectividades de la subjetividad, anterior a la gesta de la ontología como el uno por el otro, como substitución y como trascendencia desinteresada (dess-inter-esse-ment) donde se alberga el bien. Por su parte, Lévinas afirma en De otro modo que ser: "La subjetividad no es una modalidad de la esencia" (2003: 62) es irreductible a ésta y se presenta junto con el problema de la trascendencia. La subjetividad se constituye — cuando se le reconoce como gozo, cansancio, pereza - al margen de todos los términos, es su irreductibilidad a una esencia la que se posaría después dentro de un discurso. Conjuntamente, la subjetividad se concibe en esta filosofía como aquella que no podrá poseer al otro, hacerlo parte de su mismidad. Ya en Totalidad e infinito, Lévinas enuncia profundas interrogantes: "el sujeto ¿es solamente sujeto de saber y poder?, ¿no se presenta como sujeto en otro sentido?” (1977: 284).

Se podría pensar que el manifestarse del otro a la subjetividad podría aún comprenderse como presencia del otro en el Mismo, pero dicha cuestión estribaría y reincidiría en la absorción del otro por el mismo, premiando la objetividad. Sin embargo, Lévinas reclama la no implicación de la presencia como necesaria para que la subjetividad fundada en su donación hacia el otro, la responsabilidad respecto a la proximidad, sea concebida en términos de una presencia en el presente, que significaría su captación. El otro no es, pues, presencia, es senescencia.

El presente o el ahora (en francés: maintenant) es leído por Lévinas de una manera muy peculiar: literalmente como main-te- 
nant, es decir, tener a la mano, posesión que connota la presencia (main-tenance), la sensesencia refleja la inasibilidad del otro en la relación, lo Otro que queda en las obras e impide ser asimilado al Mismo por medio del conocimiento (Ravinovich, 2005: 211).

Así, la trascendencia radical que implica el otro es la desformalización del tiempo, que no será más el privilegio del presente como el tiempo constituyente de la subjetividad. Al continuo esfuerzo por permanecer, la quietud y la inmutabilidad de la esencia, se opone la senescencia, un movimiento constante, una salida hacia la exterioridad extrema que es el otro.

Pudiendo no entregarse en su presencia o guardando su "secreto", el Otro es enigma y misterio, cumpliéndose con ello su "ser" au-delà-de l'essence. Por tanto, el Otro metaontológico no podría constituir una respuesta a la pregunta por la quid-idad con la que comienza el pensar ontológico (Moreno, 1986: 43).

De esta manera, lo que se ha puesto a repensar es el marco desde el cual puede entenderse con Lévinas la idea de humanidad, cuyo particular abordaje está más bien exento del estatismo de la esencia y muda su ser en una huella, en una no-presencia, que excede todo marco de la representación. Vale la pena concentrarnos en la explicación de Ravinovich a este respecto:

El verbo ser al no poder ser hipostasiado, entonces no puede en hebreo expresar la presencia y quizás por eso Lévinas al proponer un pensamiento "de otro modo que ser" puede hacer la crítica de la primacía de la presencia en el pensamiento occidental. Es interesante que solamente ocurre la hipóstasis personal de la tercera persona singular, que es la que no está presente. Lo contrario de la presencia es la eleidad, huella por excelencia (2005: 158). 
La eleidad (illéité) es el modo que Lévinas tiene para referirse a otro que trasciende absolutamente, que permanece en constante movimiento y que sólo deja signos que pueden ser interpretados. Ésta es la extremidad de la cual se ha salvado siempre el saber, porque no se puede seguir a lo que escapa siempre. Ésta es una excedencia que marca la idea de una salida definitiva de los caminos que se habían seguido para la búsqueda del ser, pero que permanecen ajenos a esta otra relación con aquello que excede y que en esta filosofía se ha presentado como infinitud.

Queda así, por lo menos, atisbada esa recuperación de la subjetividad que, gracias al esfuerzo de Lévinas, muestra sus dos caras: en un más acá como no-saber, vulnerabilidad y soledad; en un más allá como su relación con lo infinito, fuera del ser y sin posibilidad de retornar a sí, entregada al otro, desnucleada, reducida a una posibilidad: la de la responsabilidad por el otro, que se podría llamar humanidad, subjetividad o sí mismo: "[...] lo más allá del ser que retorna y no retorna a la ontología; en cuanto enunciado, lo más allá, el infinito se convierte y no se convierte en sentido del ser" (Lévinas, 2003: 64).

\section{Bibliografía}

Bengoa Ruiz de Azúa, Javier, 2009, De Heidegger a Habermas, Barcelona, Herder.

Checchi, Tania, 1994, Un itinerario fenomenológico en la obra de Emmanuel Lévinas, Madrid, Editorial Complutense.

Derrida, Jacques, 1989, La escritura y la diferencia, Barcelona, Anthropos.

Escudero, J. Adrián, 2010, Heidegger y la genealogía de la pregunta por el ser, Barcelona, Herder. 
Forthomme, Bernard, 1979, Une philosophie de la transcendance. La métaphysique d'Emmanuel Lévinas, París, Vrin.

Fragasso, Lucas, "Jacques Derrida", en Derrida en castellano, disponible en: http://www.jacquesderrida.com.ar/comentarios/ fragasso.htm.

Heidegger, Martin, 1990, Identidad y diferencia, Barcelona, Anthropos.

Heidegger, Martin, 2000, "El nihilismo europeo", en Nietzsche II, Barcelona, Destino.

Lévinas, Emmanuel, 1977, Totalidad e infinito, Salamanca, Sígueme.

\section{Pretextos.}

,2001a, Entre nosotros. Ensayos para pensar en otro, Valencia,

, 2001b, Trascendencia y altura, Madrid, Trotta.

,2003, De otro modo que ser o más allá de la esencia, Antonio Pintor Ramos (Intro.), Salamanca, Sígueme.

Moreno, César, 1986, Proximidad, trascendencia y subjetividad en la metafenomenología de E. Levinas, Anales del Seminario de Historia de la Filosofía, VI-1986-87-88-89, Madrid, Universidad Complutense.

Ravinovich, Silvana, 2005, La huella en el palimpsesto. Lecturas de Lévinas, México, UACM.

Urabayen, Julia, 2005, Las raices del humanismo de Levinas: el judaísmo y la fenomenología, Navarra, Eunsa.

Vázquez Moro, Ulpiano, 1982, El discurso sobre Dios en la obra de E. Lévinas, Madrid, Universidad Pontificia Comillas.

(Artículo recibido el 7 de enero de 2014; aceptado el 25 de febrero de 2014) 